\title{
Células Madre Adiposas Humanas Disminuyen el Daño de la Fibrosis Hepática con Baja Persistencia de Células Trasplantadas en Ratas
}

\author{
Human Adipose Stem Cells Decrease Liver Fibrosis Damage \\ with Low Persistence of Transplanted Cells in Rats
}

\begin{abstract}
Nathaly Enciso Benavides ${ }^{1}$; Carlos Cisneros Huamaní1; Nancy Rojas Morán ${ }^{2}$; Ernesto Nava Carrión ${ }^{2}$; John Pando Mayta ${ }^{3}$; Fredy Fabián Domínguez ${ }^{1}$; José Amiel Pérez ${ }^{1}$ \& Javier Enciso Gutiérrez ${ }^{1}$
\end{abstract}

ENCISO, B. N.; CISNEROS, H. C.; ROJAS, M. N.; NAVA, C. E.; PANDO, M. J.; DOMÍNGUEZ, F. F.; PÉREZ, J.A. \& ENCISO, G. J. Células madre adiposas humanas disminuyen el daño de la fibrosis hepática con baja persistencia de células trasplantadas en ratas. Int. J. Morphol., 38(5):1496-1507, 2020.

RESUMEN: En la enfermedad hepática crónica el trasplante ortotópico es la única alternativa terapéutica actual pero es limitada por falta de donantes. Ensayos con células madre adultas en daño hepático agudo evidencian promisorios resultados. El objetivo de este trabajo fue evaluar en ratas con daño hepático crónico la efectividad de la infusión de células madre adiposas humanas (CMAd-h). Ratas con fibrosis hepática inducida por tioacetamida fueron agrupadas en: grupo I control que no recibió tioacetamida ni células madre, grupo II recibió tioacetamida y suero fisiológico i.v., grupo III recibió tioacetamida y células madre adiposas 1 x $10^{6} / \mathrm{kg}$ i.v. vía vena de la cola. La regeneración hepática histológica se evaluó por el index METAVIR, mientras las Macrophagocytus stellatus, células estrelladas aSMA+ y células colágeno I+ por inmunohistoquímica; el daño funcional se evaluó por los niveles sanguíneos de los analitos Aspartato Aminotransferasa (AST), Alanina Aminotransferasa (ALT), Fosfatasa Alcalina (ALP), úrea y nitrógeno ureico (BUN) y hemograma. Los resultados muestran atenuación del daño estructural hepático evidenciado por disminución de los nódulos, del grado de lesión histológica en el score Metavir, y disminución de Macrophagocytus stellatus, células a-SMA+ y células colágeno tipo I+; funcionalmente hay reducción moderada de AST, ALT, urea, BUN y disminución moderada de células blancas pero efecto favorable sobre el volumen corpuscular media y la hemoglobina corpuscular media. Ocho semanas después de la infusión hay escasa población de CMAd-h en el hígado. En conclusión la infusión intravenosa de CMAd-h en ratas disminuye el daño funcional y estructural de la fibrosis hepática con escasa persistencia de CMAd-h en el parénquima hepático. A nuestro conocimiento este es el primer trabajo que evalúa el efecto de las CMAd-h en el modelo daño hepático crónico murino y la persistencia de las células trasplantadas.

PALABRAS CLAVE: Células madre adiposas; Terapia celular; Fibrosis hepática; Xenotrasplante.

\section{INTRODUCCIÓN}

La fibrosis hepática comprende una serie de procesos patológicos y fisiológicos relacionados con la necrosis y degeneración de las células hepáticas después de una lesión hepática crónica, que finalmente conduce al depósito de matriz extracelular y colágeno (Li et al., 2018), se expresa como una falla hepática crónica con complicaciones graves como encefalopatía hepática, peritonitis, ascitis, que al ser diagnosticada ya es irreversible (Perez \& Stoeckle, 2016).

La progresión de la fibrosis hepática tiene un final que es la cirrosis, la cual es la sexta causa de muerte en países en desarrollo (GBD 2013 Mortality and Causes of
Death Collaborators, 2015), el riesgo de que esta avance a carcinoma hepático es mayor a $50 \%$ (Li et al.); la única solución definitiva para el estado final de la cirrosis es el trasplante ortotópico de hígado, el cual tiene severos problemas que incluye la dificultad para conseguir donantes y el rechazo inmune (Guo et al., 2016a,b).

La fibrosis hepática ocurre en respuesta a diferentes etiologías de injuria hepática crónica (Nallagangula et al., 2018), histológicamente es causada por imbalance entre la síntesis y degradación de la matriz extracelular que lleva al depósito excesivo de matriz extracelular alrededor del teji-

\footnotetext{
${ }^{1}$ Laboratorio de Cultivo Celular e Inmunología, Universidad Científica del Sur, Lima, Perú.

${ }^{2}$ Facultad de Medicina, Universidad Nacional Mayor de San Marcos, Lima, Perú.

${ }^{3}$ Instituto de Criopreservación y Terapia Celular, Lima, Perú.
} 
ENCISO, B. N.; CISNEROS, H. C.; ROJAS, M. N.; NAVA, C. E.; PANDO, M. J.; DOMíNGUEZ, F. F.; PÉREZ, J. A. \& ENCISO, G. J. Células madre adiposas humanas disminuyen el daño de la fibrosis hepática con baja persistencia de células trasplantadas en ratas. Int. J. Morphol., 38(5):1496-1507, 2020.

do hepático injuriado (Lee \& Friedman, 2011). Los fibroblastos y las células estrelladas hepáticas activados generan el mayor depósito de colágeno tipo I y $\alpha$-SMA $(\alpha-$ smooth muscleen inglés), que se acumulan en los septos al progresar la fibrosis hepática, en otros casos también el colágeno tipo IV se deposita en los espacios perisinusoidales (Mederacke et al., 2013).

La iniciación de la activación y proliferación de las células estrelladas está asociada con el incremento de varias citoquinas inflamatorias que incluyen TNF-alfa, IL-1b y IL6 , que son producidas por las Macrophagocytus stellatus (células de Kupffer) y macrófagos residentes, estas citoquinas modulan la expresión de colágeno (Sica et al., 2014).

La terapia basada en células madre ha emergido como una alternativa promisoria con evidencia acumulada de estudios clínicos y experimentales, proponiéndose como mecanismo de acción, un efecto paracrino antes que la transdiferenciación (Kwak et al., 2018), en particular las células madre mesenquimales han emergido como útiles para el tratamiento de cirrosis hepática (Hu et al., 2019).

El objetivo de este trabajo fue establecer el efecto regenerador de células madre adiposas humanas (CMAd-h) en el modelo fibrosis hepática por tiocateamida en ratas, 8 semanas después del trasplante, evaluando el aliviamento del daño estructural y funcional involucrados con la fibrosis hepática. Estos resultados permitirán explorar nuevos protocolos de ensayos empleando células madre adiposas en fibrosis hepática.

\section{MATERIAL Y MÉTODO}

Animales. Se trabajó con 24 ratas hembras Holtzman de 180-220 g compradas del Instituto Nacional de Salud del Perú (INS), que fueron mantenidas en buenas condiciones ambientales y nutricionales por un período de 15 días previos al ensayo. Este estudio se llevó a cabo en estricta conformidad con las recomendaciones de la Guía para el cuidado y uso de animales de laboratorio del Instituto Nacional de Salud del país. El protocolo de investigación para experimentación animal fue aprobado por el Comité de Ética Científica de la Universidad Científica del Sur de Lima, Perú (Resolución No. 005-2013).

Diseño experimental. Las ratas se distribuyeron en 3 grupos de 8 animales cada uno, G-I fue el grupo control sin tratamiento alguno, a los grupos II y III se les indujo fibrosis hepática empleando tioacetamida como se detalla más adelante en este trabajo; al grupo G-II se aplicó suero fisiológico, mien- tras que al grupo G-III se aplicó CMAd-h vía vena de la cola. Histopatología. Tejido hepático de $1 \times 0.5 \mathrm{~cm}$ fue fijado en solución tamponada al $10 \%$ de formol, tratados luego en un histoprocesador (Tissue-Tek; Sakura, Tokio, Japón). Posteriormente secciones seriadas de $5 \mathrm{~mm}$ de tejido parafinado fueron teñidas con hematoxilina y eosina (H\&E) (Sigma Aldrich, Steinheim, Alemania) siguiendo el protocolo de Fischer et al. (2008) y tinción tricrómica de Masson según Bardi et al. (2014). Al terminar ambas tinciones, las muestras fueron secadas y se examinaron con un microscopio (Nikon Eclipse T 200).

Inmunohistoquímica. La inmunohistoquímica se realizó en cortes obtenidos de las mismas muestras utilizadas para histopatología, luego de la desparafinación se aplicó un protocolo de recuperación antigénica empleando buffer citrato pH 6,0 en horno microondas (LG) a potencia 4, por 5 minutos; luego, se siguió el protocolo del fabricante del kit (Invitrogen). Para el registro de fotografías de la inmunocitoquímica se utilizó un microscopio NIKON modelo Eclipse T 200, con cámara fotográfica Canon incorporada y software para procesamiento de imágenes.

Células madre adiposas humanas. Con el fin de aislar CMAd-h, se obtuvo 15 gramos de tejido graso de descarte pos quirúrgico del epiplón menor, de un varón de 38 años de edad, libre de agentes virales infectocontagiosos, sometido a resección de apéndice, contando con consentimiento informado de donación en el Hospital de origen. La muestra fue depositada de inmediato en un medio de cultivo de transporte constituido por DMEM-F12 (Invitrogen), al cual se le adicionó $10 \%$ de suero fetal bovino (SFB), penicilinaestreptomicina-anfotericina $\mathrm{B}$, para luego ser transportada al Laboratorio de Cultivo Celular e Inmunología de la misma Universidad.

En el laboratorio, el tejido adiposo fue tratado con una solución de colagenasa tipo I al 0,75 \% (Invitrogen Inc, USA), el sobrenadante se centrifugó a 700 g por 15 minutos y el sedimento fue sembrado en placas de cultivo celular (Falcon, USA) de 6 pocitos en medio DMEM-F12 con 10 $\%$ de SFB, penicilina-estreptomicina y anfotericina B (Millipore, USA). Se realizó cambios de medio cada 48 horas y cuando alcanzaron más de $70 \%$ de confluencia se realizó el siguiente pasaje a Flask de $175 \mathrm{~cm} 2$, previo desprendimiento de la placa mediante tripsina al 0,25\%. Células del segundo pasaje fueron remitidas para caracterización y xenotrasplante.

La caracterización se realizó identificando características morfológicas como la adhesión al plástico y forma fusiforme determinadas por microscopía invertida (Eclipse TI-S, Nikon) con registro en cámara fotográfica digital (Sigh 
ENCISO, B. N.; CISNEROS, H. C.; ROJAS, M. N.; NAVA, C. E.; PANDO, M. J.; DOMÍNGUEZ, F. F.; PÉREZ, J. A. \& ENCISO, G. J. Células madre adiposas humanas disminuyen el daño de la fibrosis hepática con baja persistencia de células trasplantadas en ratas. Int. J. Morphol., 38(5):1496-1507, 2020.

DS-L3, Nikon), y microscopía electrónica de barrido (MEB INSPECT S50. FEI, Hillsboro, Oregón. USA) siguiendo el protocolo descrito por Miko et al. (2015), empleando células de segundo pasaje que crecieron en cubreobjetos hasta alcanzar $70 \%$ de confluencia.

La diferenciación a 4 linajes se realizó mediante kits de diferenciación adipogénica, osteogénica, condrogénica y neurogénica (Invitrogen), mientras que el inmunofenotipo fue establecido por citometría de flujo (Guava easy CyteTM, Millipore) empleando $1 \mathrm{~mL}$ de muestra. Previamente se realizó el recuento en contador citométrico (SpecterTM, Millipore).

La citometría se realizó empleando el kit Flow CellectTM Human Mesenquimal Stem Cell Characterization kit (Millipore) conteniendo los siguientes marcadores: CD105FITC, CD90PE, CD19PECy5, así como los monoclonales CD34EDC (Beckman Coulter) y CD45PECy7 (E Bioscience); el análisis de datos se llevó a cabo en gráficos Dot Plot y en Histogramas, donde, en los gráficos Dot Plot se mostraron las poblaciones celulares de la siguiente manera: SSC vs FSC, CD34 vs CD19, CD45 vs CD19, CD105 vs CD90, mientras que en los Histogramas se mostró la expresión de CD105 y CD90 comparado con sus respectivos controles negativos. Se trabajó en el citómetro de flujo Guava (Milipore).

Infusión intravenosa. Se realizó mediante infusión de CMAd$\mathrm{h}$ por la vena caudal de la cola de las ratas. La dosis de células trasplantadas fue de $1 \times 10^{6} / \mathrm{kg}$ por vía endovenosa empleando una jeringa de $1 \mathrm{~mL}$ con aguja $27 \mathrm{G} 1 / 2$ " y las células fueron diluidas en suero fisiológico.

Inducción de injuria crónica. La fibrosis hepática fue inducida mediante tioacetamida (TAA)(Sigma, Cat. 163678) por 24 dosis de $220 \mathrm{mg} / \mathrm{kg}$ intraperitoneal (ip), una dosis cada semana, a los grupos G-II y G-III, en cambio el grupo control G-I recibió suero fisiológico. Siete días después de aplicada la última dosis de TAA se realizó la eutanasia de los animales, mediante pre-tratamiento con la asociación xylacina/ketamina $(10 \mathrm{mg} / \mathrm{kg})$ y posterior saturación con cloroformo.

\section{Efectividad de la terapia}

Efecto funcional. A los grupos G-II y G-III se les extrajo sangre venosa 15 días y 8 semanas después de la infusión de CMAd-h para determinar los valores sanguíneos de Transaminas oxaloacetica (TGO), Transaminasa piruvica (TGP), Fosfatasa alcalina (ALP), nitrógeno ureico de la sangre (BUN), ceratinina, proteínas totales, albúmina y globulinas. Inmediatamente a la extracción de sangre se obtuvo el suero empleando una centrífuga a $3000 \mathrm{rpm}$ (Boeco), las pruebas bioquímicas para medir función hepá- tica y renal fueron determinadas inmediatamente mediante un método cinético empleando un analizador bioquímico semi automatizado (Rayto. RT-1904 CV). Las mismas muestras se usaron para realizar hemograma empleando un analizador hematológico automatizado con software para animales (Rayto RT-7600).

Efecto estructural. Al completar las 24 dosis de tiocetamida los animales del grupo G-II fueron sacrificados para estudios estructurales mediante histopatología de tejido hepático parafinado de $5 \mu \mathrm{m}$ de espesor con tinción $\mathrm{H} / \mathrm{E}$ para estadificar la fibrosis por el método Metavir (Goodman, 2007), y tinción de masson para detectar tejido fibroso.

Mediante inmunohistoquímica se determinó la población de Macrophagocytus stellatus, células estrelladas activadas productoras de $\alpha$-SMA y producción de colágeno tipo I empleando anticuerpos monoclonales específicos anti CD68 para Macrophagocytus stellatus, anti a-SMA para células estrelladas y anti colágeno tipo I (Invitrogen), mientras que las células madre mesenquimales humanas fueron detectadas empleando un anticuerpo monoclonal anti-núcleo de célula humana (Anti-Nuclei Antibody, clone 235-1 | MAB1281, Merck-Millipore, USA) en todos los casos empleando una dilución 1:100 e incubados por toda la noche a $4^{\circ} \mathrm{C}$ en cámara húmeda.

Análisis estadístico. Los resultados enzimáticos han sido cuantificados en UI/L, con respecto a la úrea y BUN en mg/ $\mathrm{dL}$ y las poblaciones celulares en sangre han sido consideradas por 103 células/ $\mu \mathrm{L}$. La normalidad de los resultados fueron analizados usando la prueba de normalidad de D'Angostino \& Pearson usando el software GraphPad Prism 7.0, y según su distribución, estos resultados fueron analizados usando Ttest o Mann-Whitney, en el mismo software. Los datos son expresados como mediat Desviación Standard. La significancia estadística fue considerada como $p<0.05$.

\section{RESULTADOS}

Aislamiento y caracterización de células madre adiposas. A partir de tejido adiposo de epiplón menor de hombre adulto se logró aislar, caracterizar y expandir CMAd-h como se observa en la Figura 1, estas células fueron adherentes con morfología fusiforme a la microscopía invertida (1a), mientras que por microscopía electrónica de barrido se observó lamelipodios con fibras de estrés ratificándose la morfología fusiforme (1b). Las células aisladas fueron diferenciadas a los linajes: osteogénico (A), adipogenico (B), condrogénico $(\mathrm{C})$, además de diferenciarse al linaje neurogénico (D) (Fig. 2). La muestra para citometría de flu- 
ENCISO, B. N.; CISNEROS, H. C.; ROJAS, M. N.; NAVA, C. E.; PANDO, M. J.; DOMíNGUEZ, F. F.; PÉREZ, J. A. \& ENCISO, G. J. Células madre adiposas humanas disminuyen el daño de la fibrosis hepática con baja persistencia de células trasplantadas en ratas. Int. J. Morphol., 38(5):1496-1507, 2020.

jo tenía 6.06x103/ $\mu \mathrm{L}$ de células nucleadas, no expresaron los marcadores de superficie CD19, CD34, Cd45, en cam-

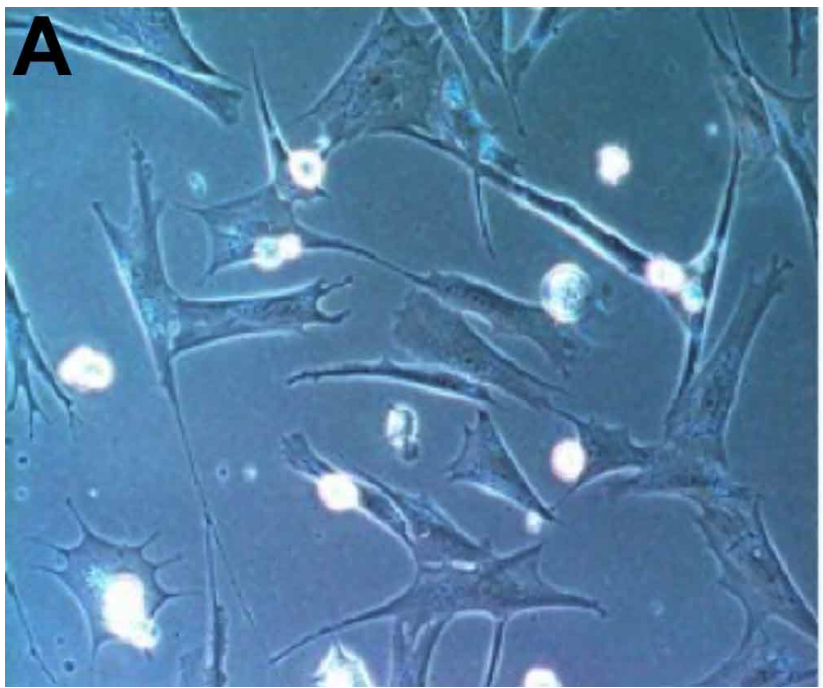

bio más del $90 \%$ fueron positivas a los marcadores CD90 y CD105 (Fig. 3).

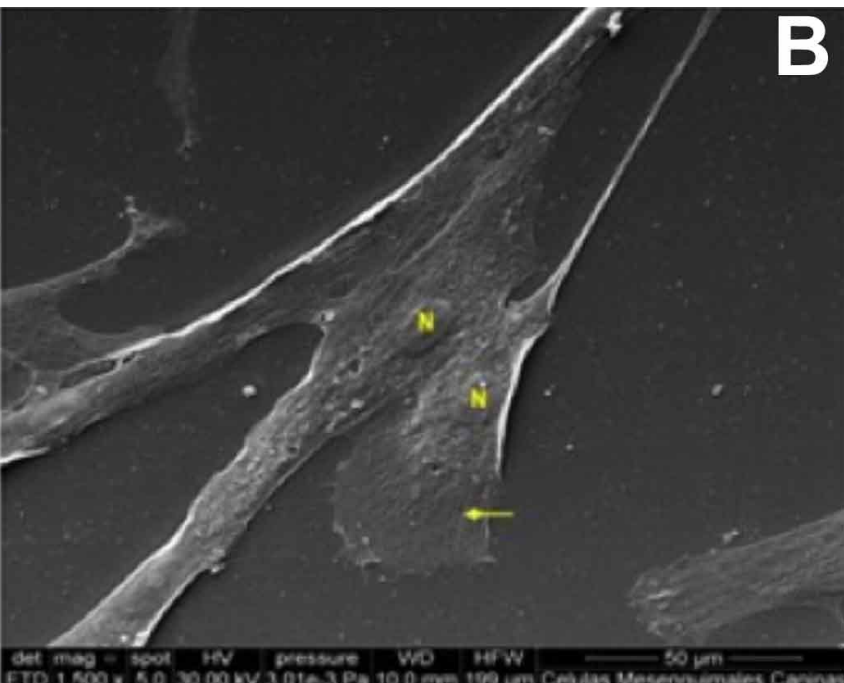

Fig.1. Cultivo primario en pasaje 2 de CMAd-h. (a) Morfología fusiforme y adherencia al plástico. 40X. Microscopía invertida. (b) Células fusiformes unidas y sus respectivos núcleos(N). La flecha señala un lamelipodio donde se visualizan fibras de estrés (microfilamentos de actina) (Flecha). Microscopía electrónica de barrido. 1500X.
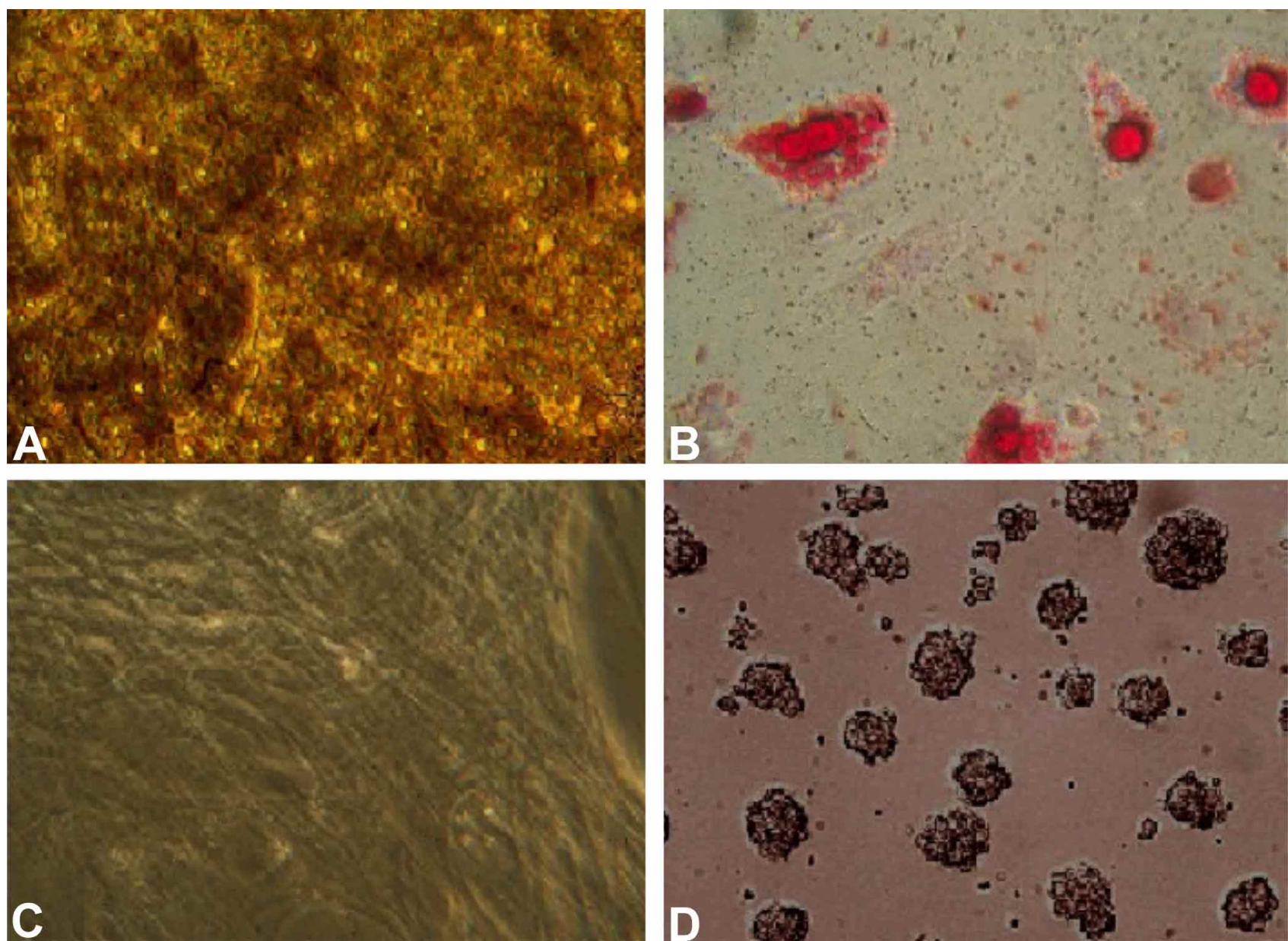

Fig. 2. Diferenciación multilinaje de CMAd-h. (A) Diferenciación en linaje osteogénico, notar depósito de mineral; (B) linaje adipogénico; (C) linaje condrogénico; (d) neuroesferas de linaje neurogénico. 20X. 

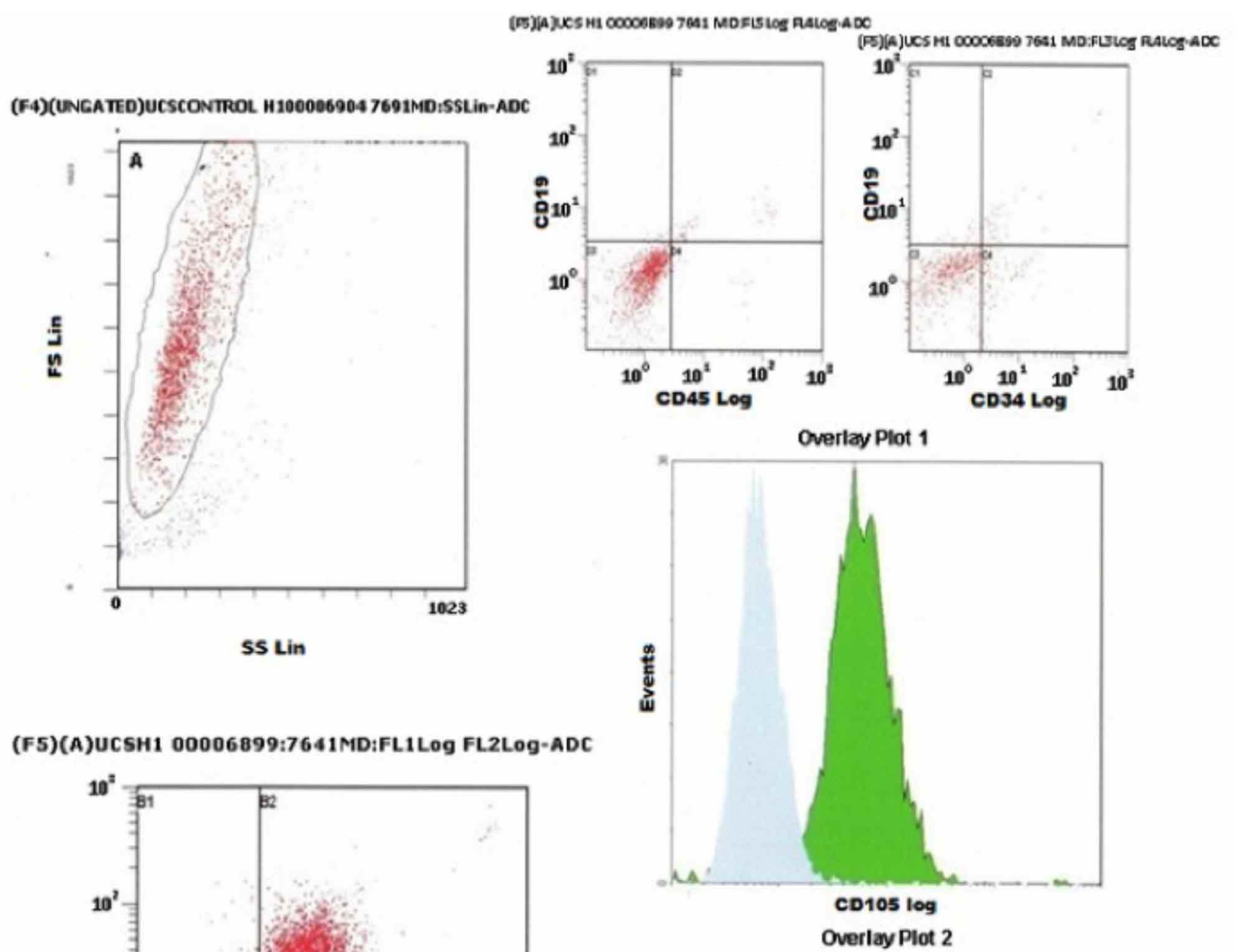

(F5)(A)UCSH1 00006899:7641MD:FL1Log FL2Log-ADC
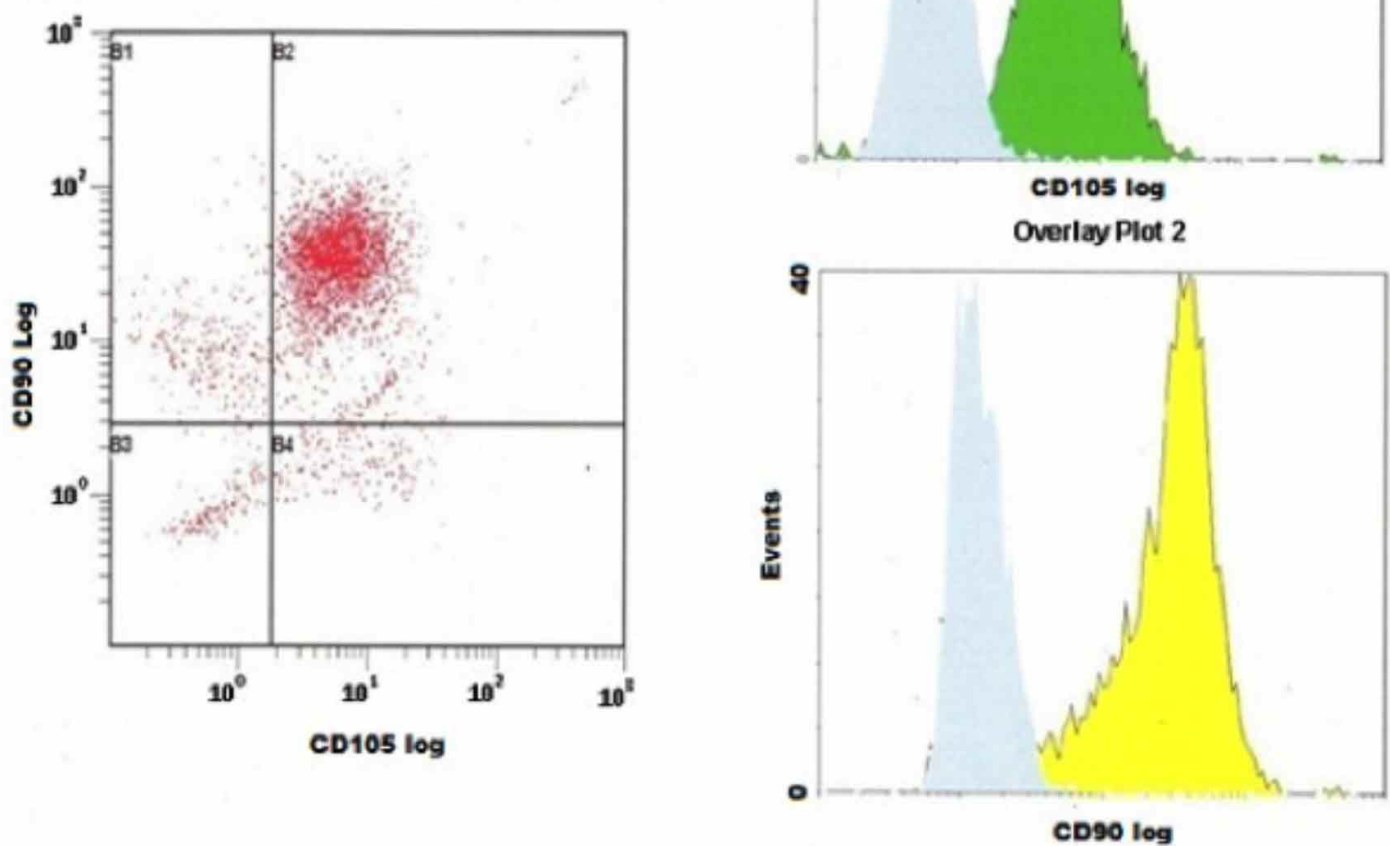

Fig. 3. Dot plot FSC vs SSC Gate A: Selección de Células excluyendo debris. Regiones D y C muestran no expresión de CD19, CD34, Cd45. Región B muestra la población de células mesenquimales doble positivo a CD90 y CD105. Histogramas (Overlay Plot 1 y 2) muestran positividad de las células para CD105 y CD90.

\section{Efectos del trasplante de CMAh}

Peso de los animales. Se observó diferencia significativa entre el peso de las ratas que recibieron CMAd-h y las de control con suero fisiológico a los 15 días pos-trasplante, en cambio al final del experimento no hay diferencias de peso entre las ratas de los grupos G-II y G-III (datos no mostrados). 


\section{Efectividad de la terapia}

Efecto sobre células sanguíneas. A las 8 semanas pos infusión de CMAd-h, se determinó diferencia significativa en las poblaciones de la serie blanca (leucocitos totales, linfocitos, monocitos, segmentados y eosinófilos) ( $p>0,05)$ (Fig. 4) expresándose en disminución de dichas poblaciones en los animales que fueron tratados con CMAd-h. También hubo diferencia significativa en Volumen Corpuscular Media(VCM) y Hemoglobina Corpuscular Media (HCM) ( $p>0,005$ ) expresado por incremento de VCM y disminución de HCM en los animales que recibieron CMAd-h (Fig. 5). Sin embargo, al medir el efecto temprano de las CMAdh, quince días pos infusión, se encontró que había disminución de leucocitos totales y de linfocitos, en cambio las plaquetas se incrementan inicialmente normalizándose a la octava semana de la infusión celular (Datos no mostrados).

Efecto sobre la función hepática y renal. En cuanto a la bioquímica sanguínea a las 8 semanas pos infusión de las CMAd-h se encontró diferencia significativa en los niveles de urea y BUN ( $>00,005)$ así mismo en las transaminasas TGO y TGP $(p>0,05)$ evidenciando en ambos casos disminución por efecto de las CMAd-h (Fig. 6).
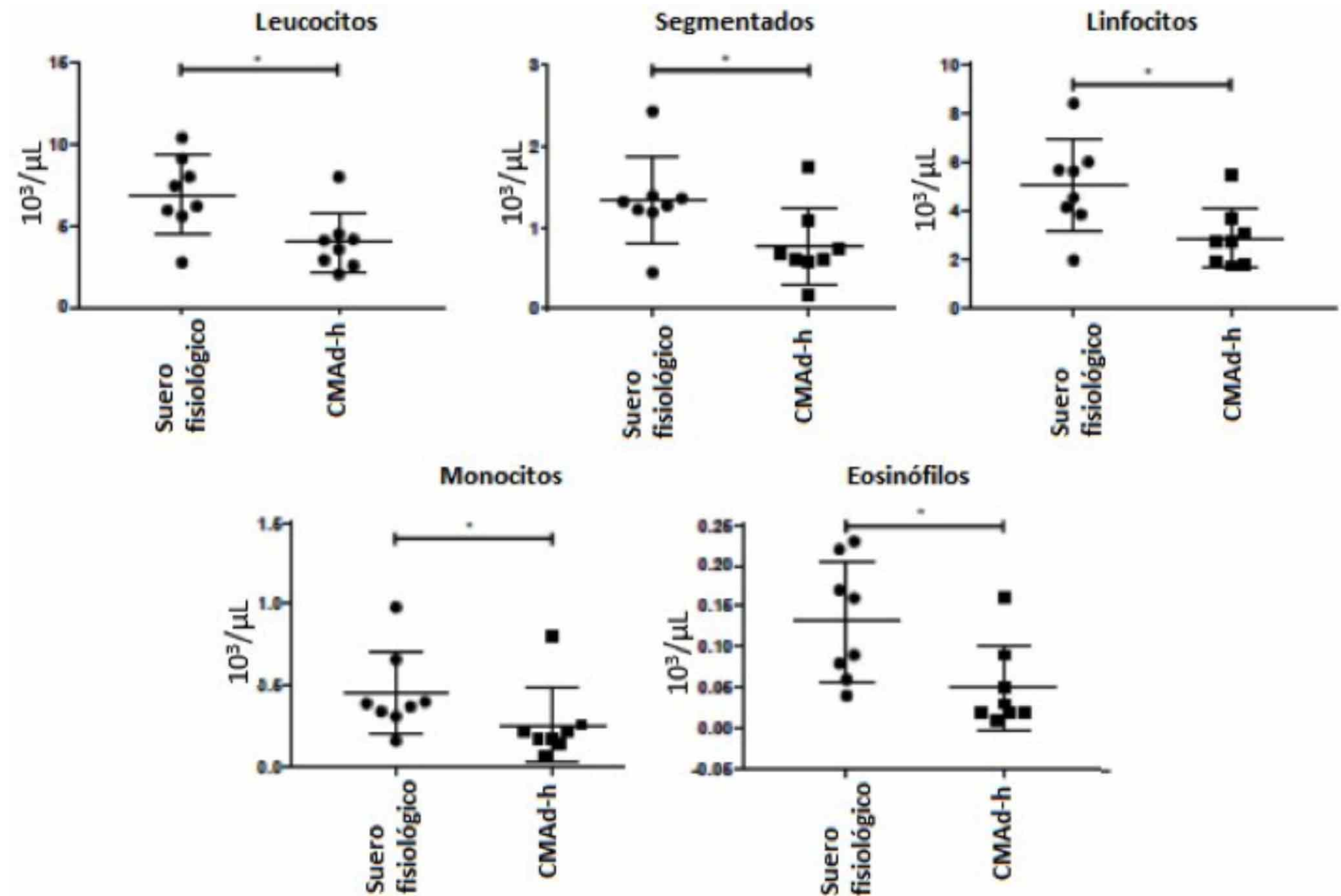

Fig. 4. Poblaciones de células blancas de la sangre 8 semanas después de la infusión de suero físiológico y CMAd-h en ratas con fibrosis hepática inducida por tioacetamida. 
VCM

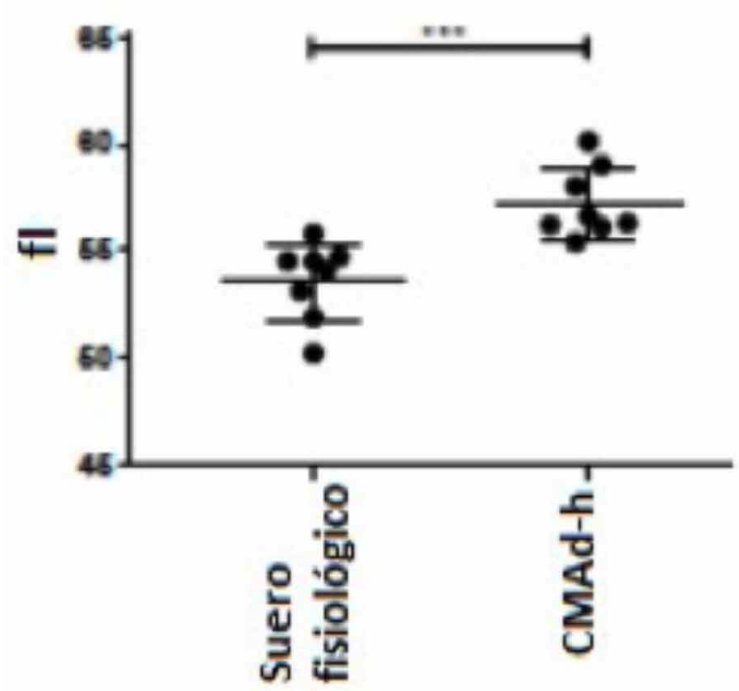

\section{HCM}

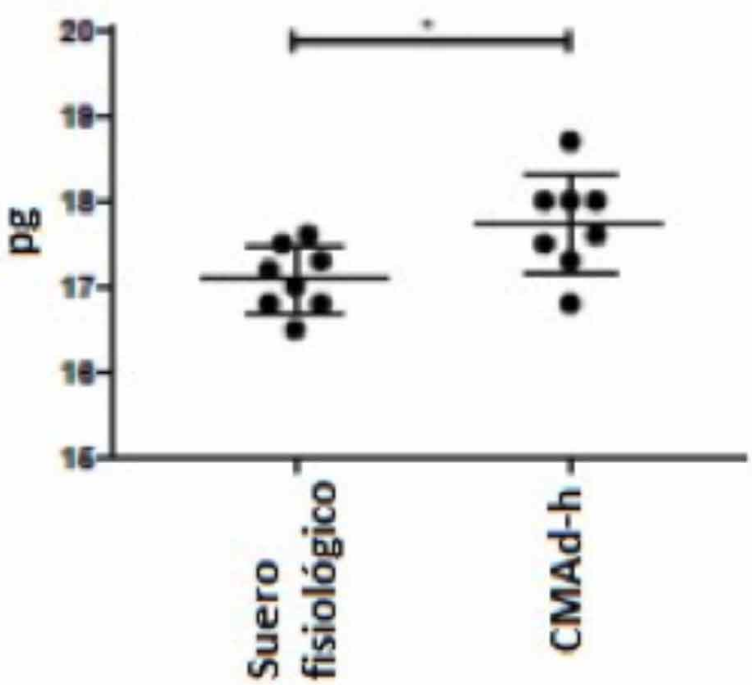

Fig. 5. Diferencias en VCM y HCM en los grupos control y con infusión de CMAd-h.
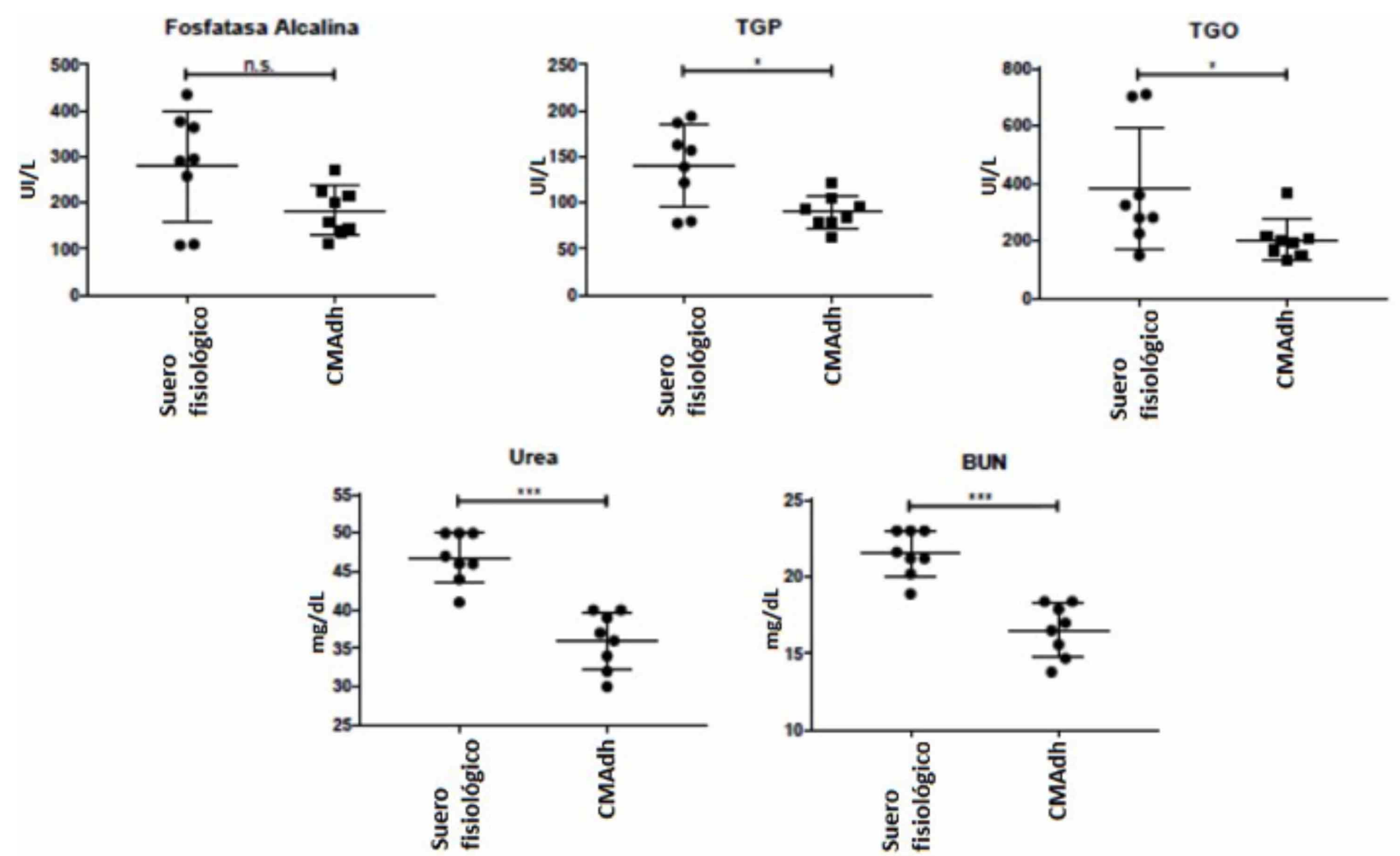

Fig. 6. Difererencias estadísticas entre los grupos sin y con tratamiento de CMAd-h en relación a la función hepática (FA, TGP, TGO) $\mathrm{p}>0,05$ y renal (urea, BUN) $\mathrm{p}>0.005$. 

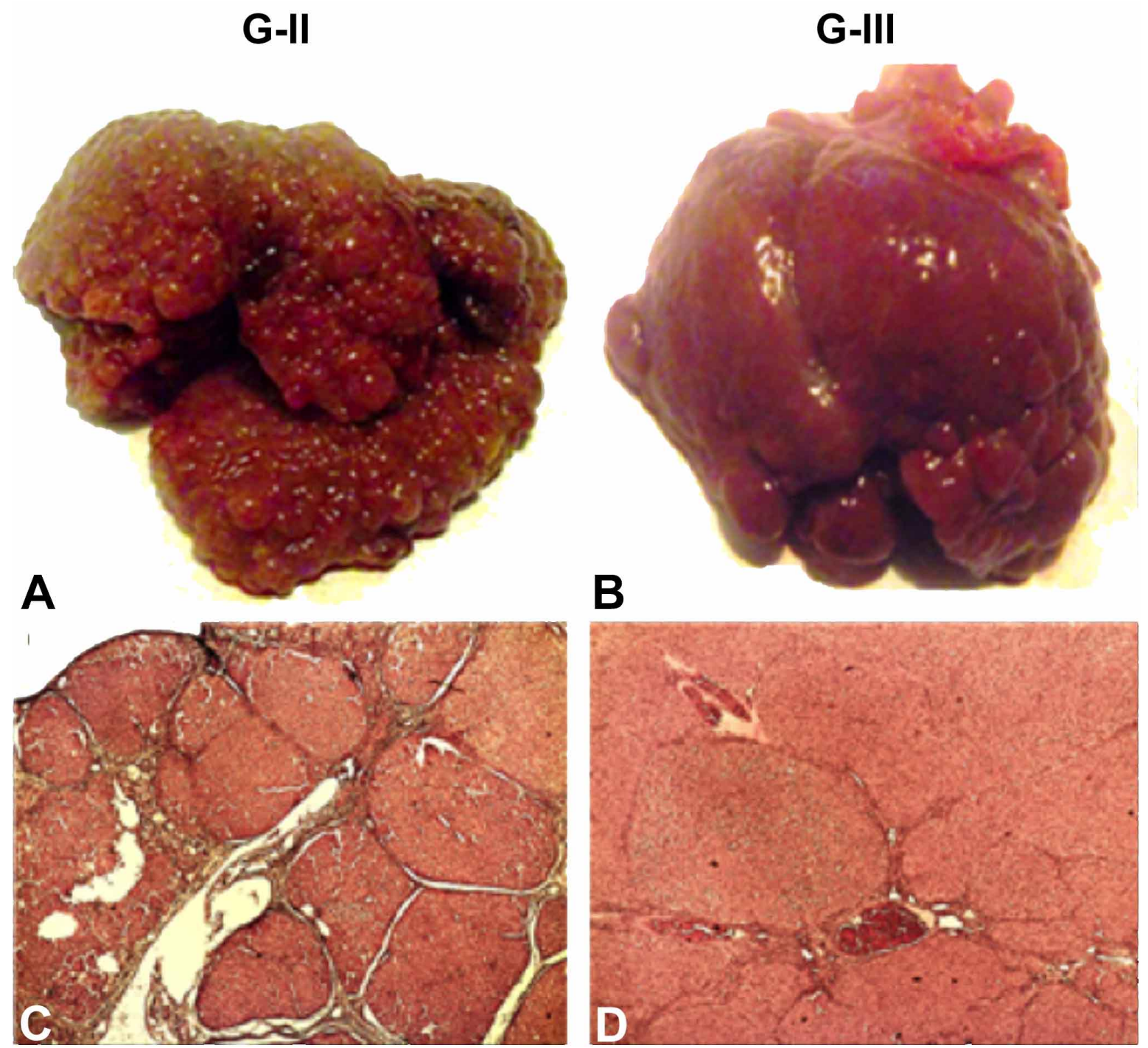

Fig. 7. Hígado. G-II grupo que recibió TAA y suero fisiológico, G-III grupo que recibió TAA y CMAd-h. (a) múltiples micro y macro nódulos en todo el órgano. (b) disminución de los micro y macronódulos. (c) Histologia. Abundantes septos fibrosos que delimitan micronódulos. Tinción H/E. 10X. (d) Histología. Disminución de septos fibrosos y escasos micronódulos. Tinción H/E. 10X.

Mediante inmunohistoquímica se apreció disminución de la población de Macrophagocytus stellatus (Fig. 9e,f), células colágeno I-positivas (Fig. 8g,h) y células a-SMA positivas (Fig. 8c,d) 8 semanas después de la infusión de CMAd-h.

Detección de células madre adiposas. Por inmunohistoquímica se demostró escasa presencia de dichas células en hígado de ratas con fibrosis inducida por tioacetamida a nivel de parénquima y tejido fibroso 8 semanas pos infusión (Fig. 9a,b). Cuando se pesquisó las células madre en otros órganos fueron detectadas en riñones (Fig. 9c) y en cerebro (Fig. 9d).

\section{DISCUSIÓN}

Las células madre de tejido adiposo utilizadas en este estudio, presentaron características mínimas para ser consideradas como tales por la International Society Cellular Therapy (ISCT) (Dominici et al., 2006), además de diferenciación a linaje neurogénico; en tanto que a nivel ultraestructural se confirmó la morfología fusiforme de células madre mesenquimales y presencia de lamelipodios con fibras de estrés, lo que valida que las células usadas en este trabajo fueron CMAd-h. 


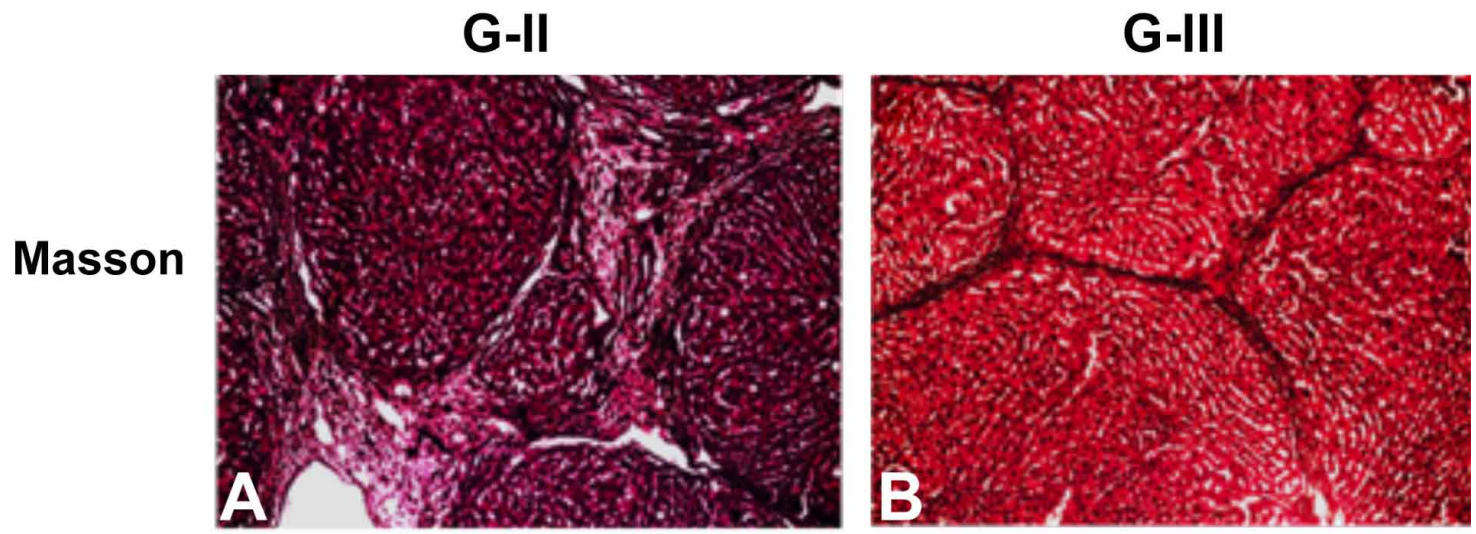

a-SMA
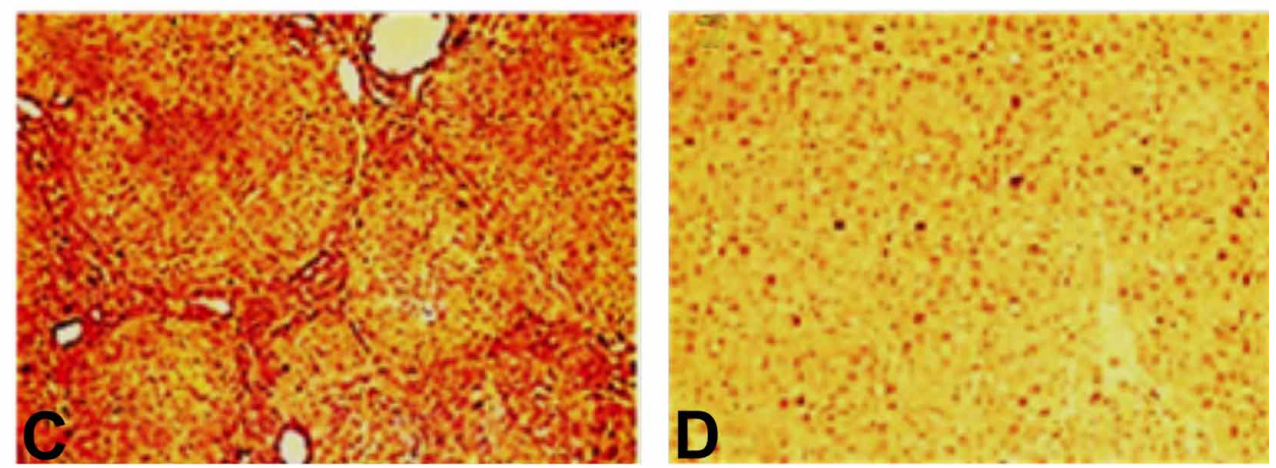

CD-68


\section{Colágeno-I}
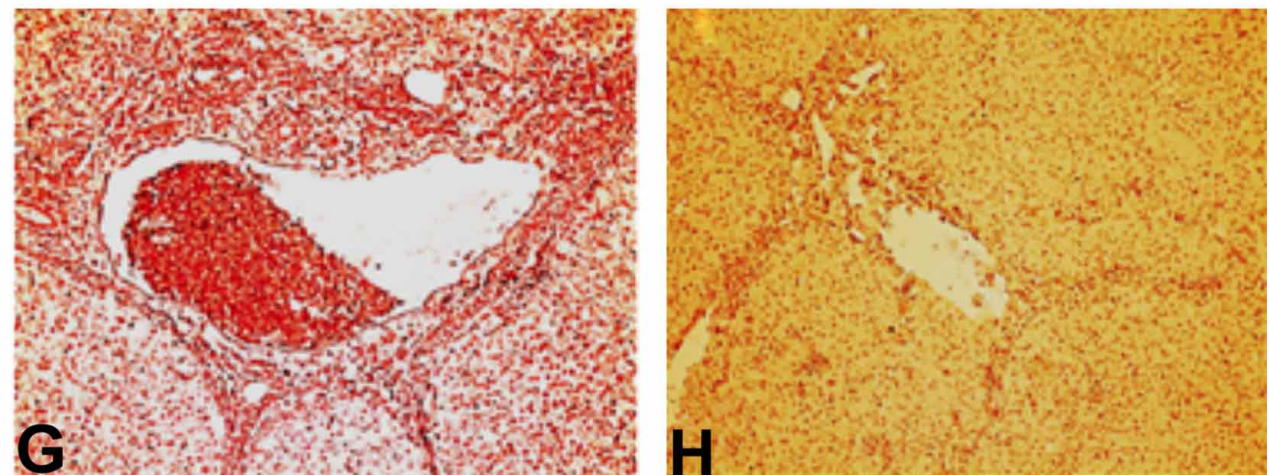

Fig. 8. Hígado. G-II grupo control sin CMAd-h, G-III grupo experimental que recibió CMAd-h. (a) abundante tejido fibroso en septos de los nódulos hepáticos. Tinción de Masson. 20x. (b) menor cantidad de tejido fibroso en delgados septos. Tinción de Masson. 10X. (c) Abundantes células a-SMA + en parénquima. IHQ. (d) escasas células a-SMA + en parénquima. IHQ. (e) abundantes células CD68+ en septos y parénquima. IHQ. (f) disminución de células CD68+ en septos y parénquima. IHQ. (g) abundantes células colágeno-I+ en tejido fibroso de pared de vena central. IHQ. (h) poca cantidad de células colágeno-I+en septos y parénquima. IHQ. 

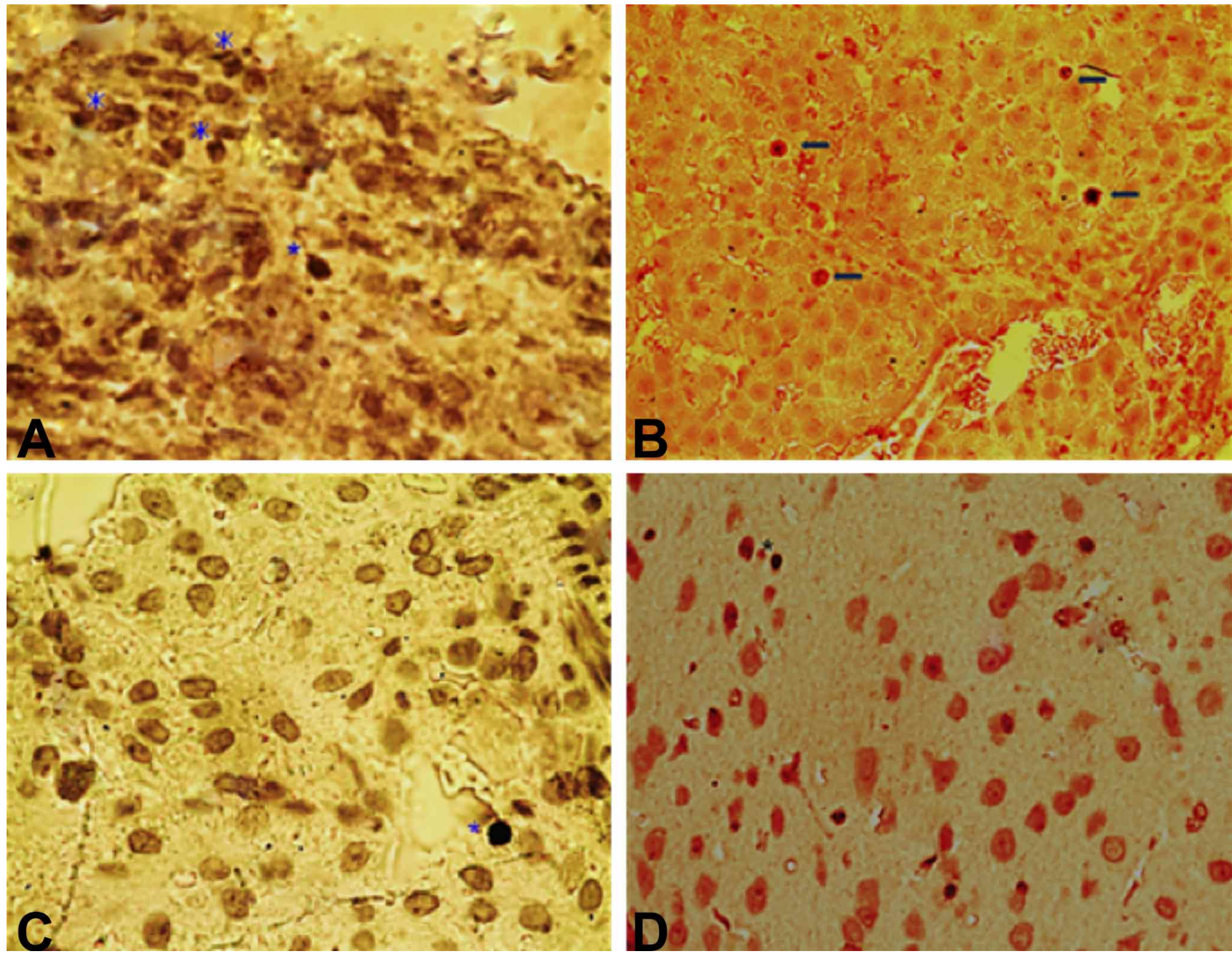

Fig. 9. CMAd-h (asterisco) trasplantadas a ratas. (a) en el tejido fibroso de los septos, 40X. (b) en parénquima hepático (flechas).40X. Detección de células de linaje humano en riñón, 40X, y (c) en cerebro, 40X (d). Inmunohistoquímica.

El xenotrasplante de estas CMAd-h en ratas por vía intravenosa fue exitoso, habiéndose detectado por inmunohistoquímica presencia de células en hígado, riñón y cerebro de ratas como un hallazgo. En hígado con fibrosis la implantación se distribuyó mayoritariamente en las paredes de los vasos sanguíneos, similar a lo descrito por Harn et al. (2012) en tanto que Zhu et al. (2013) detectaron CMAd-h en la región portal del hígado, y en menor cantidad en el parénquima hepático.

Un hallazgo de este trabajo es el incremento de peso de las ratas solo hasta los 15 días pos-trasplante, pues no se sostiene con el tiempo durante las ocho semanas que duró este estudio. Este efecto no ha sido descrito dentro de la literatura revisada, consideramos que se debe a la acción antinflamatoria y en consecuencia también analgésica, que brinda un estado transitorio de bienestar que pudiera ac- tuar incrementando el consumo de alimento y optimizando algunas vías metabólicas de las proteínas, carbohidratos y lípidos.

Por otro lado, según el protocolo de este trabajo, el efecto sobre las células sanguíneas se expresó por una disminución moderada de células blancas dentro de ellas linfocitos en ratas tratadas con CMAd-h, lo cual podría explicarse por estudios que demuestran que estas células son capaces de regular la respuesta inmune suprimiendo la proliferación de LT, la citotoxicidad y secreción de citoquinas, regulando las funciones de linfocitos $\mathrm{T}$ regulatorios $\mathrm{e}$ inhibiendo la proliferación de linfocitos B (Gao et al., 2016), así como también por su efecto de preservar la actividad de las células NK (Blanco et al., 2016), de estimular linfocitos T reguladores(Haddad \& Saldanha-Araujo, 2014) y suprimir la respuesta inmune en un contexto inflamato- 
rio (Wang et al., 2014), como es el caso de la fibrosis hepática inducida por tioacetamida (Nascimento et al., 2018).

Por otro lado, en otros trabajos se ha demostrado que el antígeno clase I del complejo mayor de histocompatibilidad no clásico (HLA-G), está involucrado en las propiedades inmunosupresoras de las células madre mesenquimales en trasplante de órganos y aloinjertos fetales, a través de la interacción con los receptores inhibitorios sobre células dendríticas (DC), células natural killer (NK), y linfocitos-T, así mismo, ejerce un efecto inmunosupresor mediante la inducción de apoptosis de las células T- CD8 y la inhibición de la proliferación de células T-CD4 (Kordelas et al., 2018), consideramos que todos estos trabajos pueden explicar lo que reportamos en este estudio, que se refiere a la disminución de las Macrophagocytus stellatus y al disminuir estas, disminuyen también las moléculas reguladoras de la proliferación de las células estrelladas y de la producción de colágeno tipo I responsables de la fibrosis hepática.

Aqui reportamos un aliviamento de la función hepática del hígado fibroso al disminuir las enzimas TGO y TGP en ratas con fibrosis que recibieron trasplante de CMAd-h, en comparación a las que no recibieron estas células. Estos resultados son comparables con otro trabajo en el cual, el xenotrasplante de células madre mesenquimales porcinas de tejido adiposo fueron trasplantadas a conejos con cirrosis inducida por tetracloruro de carbono, mejorando similarmente la función hepática en el receptor (Zhu et al.). Sin embargo no es posible prever la duración de este nuevo perfil enzimático, haciendo falta nuevos estudios con mayor tiempo de seguimiento posterior a la terapia celular, y dosis repetidas de células madre.

Los resultados de este trabajo ratifican la importancia de las células estrelladas a-SMA positivas en esta enfermedad, pues su población está incrementada en los animales que no recibieron CMAd-h mientras que disminuyen en el grupo con terapia de CMAd-h, similar a lo descrito en otros trabajos (Hao et al., 2017) y sustentado en que estas células juegan un rol clave en la patogénesis de la fibrosis hepática (Ismail \& Pinzani, 2009). Esta disminución de células estrelladas puede explicarse por la simultanea inhibición de las Macrophagocytus stellatus en el grupo tratado con CMAd-h, células que secretan citoquinas y quimioquinas para la activación y proliferación de las células estrelladas como han demostrado en otros trabajos (Ebrahimi et al., 2016).

Todos estos resultados, evidencian que las CMAd$\mathrm{h}$ reducen el tejido fibroso hepático y alivian la función del hígado en ratas con fibrosis hepática, mediante inhibición de Macrophagocytus stellatus, de células estrelladas (alfaSMA+) y células productoras de colágeno tipo I, que junto a la presencia de escasas células trasplantadas, sugiere que el mecanismo de acción de las CMAd-h sobre la fibrosis hepática sería paracrino, participando posiblemente citoquinas y quimioquinas antiinflamatorias.

\section{AGRADECIMIENTOS}

Trabajo financiado por el Consejo Nacional de Ciencia y Tecnología del Perú mediante contrato de Subvención No. 409-2012 CONCYTEC-OAJ, por el convenio 053FIDECOM-INNOVATEPERU-PIMEN-2018 y convenio 104-2018-FONDECYT-BM-IADT-AV. Se agradece a Alex Choque Matos por su apoyo en la toma de algunas muestras de tejido adiposo para aislamiento de células madre.

ENCISO, B. N.; CISNEROS, H. C.; ROJAS, M. N.; NAVA, C. E.; PANDO, M. J.; DOMÍngUEZ, F. F.; PÉREZ, J. A. \& ENCISO, G. J. Human adipose stem cells decrease liver fibrosis damage with low persistence of transplanted cells in rats. Int. J. Morphol., 38(5):1496-1507, 2020.

SUMMARY: In chronic liver disease, orthotopic transplantation is the only current therapeutic alternative but it is limited due to lack of donors. Trials with adult stem cells in acute liver damage show promising results. The aim of this work was to evaluate the effectiveness of human adipose stem cell (h-ASC) infusion in rats with chronic liver damage. Rats with thioacetamideinduced liver fibrosis were grouped into: group I control that did not receive thioacetamide and h-ASC, group II received thioacetamide and saline i.v., group III received thioacetamide and h-ASC 1 x 10\% $\mathrm{kg}$ i.v. via tail vein. Histological liver regeneration was evaluated by METAVIR index, while Macrophagocytus stellatus (Kupffer cells), stellate cells a-SMA+ and collagen I+ cells by immunohistochemistry; functional damage was evaluated by blood levels of the analytes Aspartate Aminotransferase (AST), Alanine Aminotransferase (ALT), Alkaline Phosphatase (ALP), Urea and Blood Urea Nitrogen (BUN) and hemogram. The results show attenuation of structural liver damage evidenced by decreased nodules, degree of histologic injury on Metavir score, and decreased Macrophagocytus stellatus, a-SMA+ cells and type I+ collagen cells; functionally there is moderate reduction of AST, ALT, urea, BUN and moderate decrease of white cells but favorable effect on mean corpuscular volume and mean corpuscular hemoglobin. Eight weeks after infusion there is a small population of h-ASC in the liver. In conclusion, intravenous infusion of h-ASC in rats reduces functional and structural damage of hepatic fibrosis with low persistence of $h$ ASC in the liver parenchyma. To our knowledge this is the first work that evaluates the effect of h-SC in the model of chronic murine liver damage and the persistence of transplanted cells.

KEY WORDS: adipose stem cells; cell therapy; hepatic fibrosis, xenotransplantation. 


\section{REFERENCIAS BIBLIOGRÁFICAS}

Bardi, D. A.; Halabi, M. F.; Hassandarvish, P.; Rouhollahi, E.; Paydar, M.; Moghadamtousi, S. Z.; Al-Wajeeh, N. S.; Ablat, A.; Abdullah, N. A. \& Abdulla, M. A. Andrographis paniculata leaf extract prevents thioacetamide-induced liver cirrhosis in rats. PLoS One, 9(10):e109424, 2014.

Blanco, B.; Herrero-Sánchez, M. C.; Rodríguez-Serrano, C.; GarcíaMartínez, M. L.; Blanco, J. F.; Muntión, S.; García-Arranz, M.; Sánchez-Guijo, F. \& Del Cañizo, C. Immunomodulatory effects of bone marrow versus adipose tissue-derived mesenchymal stromal cells on NK cells: implications in the transplantation setting. Eur. J. Haematol., 97(6):528-37, 2016.

Dominici, M.; Le Blanc, K.; Mueller, I.; Slaper-Cortenbach, I.; Marini, F. C.; Krause, D. S.; Deans, R. J.; Keating, A.; Prockop, D. J. \& Horwitz, E. M. Minimal criteria for defining multipotent mesenchymal stromal cells. The International Society for Cellular Therapy position statement. Cytotherapy, 8(4):315-7, 2006.

Ebrahimi, H.; Naderian, M. \& Sohrabpour, A. A. New concepts on pathogenesis and diagnosis of liver fibrosis; a review article. Middle East J. Dig. Dis., 8(3):166-78, 2016.

Fischer, A. H.; Jacobson, K. A.; Rose, J. \& Zeller, R. Hematoxylin and eosin staining of tissue and cell sections. CSH Protoc., 2008:pdb.prot4986, 2008.

GBD 2013 Mortality and Causes of Death Collaborators. Global, Regional, and National age-sex specific all-cause and cause-specific mortality for 240 causes of death, 1990-2013: a systematic analysis for the Global Burden of Disease Study 2013. Lancet, 385(9963):117$71,2015$.

Guo, F.; Chiu, S. M.; Motan, D. A. L.; Zhang, Z.; Chen, L.; Ji, H. L.; Tse, H. F.; Fu, Q. L. \& Lian, Q. Mesenchymal stem cells and immunomodulation: current status and future prospects. Cell Death Dis., 21(7):e2062, 2016 b.

Guo, Y.; Chen, B.; Chen, L. J.; Zhang, C. F. \& Xiang, C. Current status and future prospects of mesenchymal stem cell therapy for liver fibrosis. J. Zhejiang Univ. Sci. B, 17(11):831-41, 2016a.

Haddad, R. \& Saldanha-Araujo, F. Mechanisms of T-cell immunosuppression by mesenchymal stromal cells: what do we know so far? Biomed Res. Int., 2014:216806, 2014.

Hao, T.; Chen, J.; Zhi, S.; Zhang, Q.; Chen, G. \& Yu, F. Comparison of bone marrow-vs. adipose tissue-derived mesenchymal stem cells for attenuating liver fibrosis. Exp. Ther. Med., 14(6):5956-64, 2017.

Harn, H. J.; Lin, S. Z.; H.; Hung, S. H.; Subeq, Y. M.; Li, Y. S.; Syu, W. S.; Ding, D. C.; Lee, R. P.; Hsieh, D. K.; Lin, P. C.; et al. Adiposederived stem cells can abrogate chemical-induced liver fibrosis and facilitate recovery of liver function. Cell Transplant., 21(12):275364, 2012.

Hu, Z.; Xia, Y.; Hong, S. G.; Thomas, E. \& Li, D. Stem cells and liver diseases. Stem Cells Int., 2019:9271746, 2019.

Ismail, M. H. \& Pinzani, M. Reversal of liver fibrosis. Saudi J. Gastroenterol., 15(1):72-9, 2009.

Kordelas, L.; da Silva Nardi, F.; Wagner, B.; Ditschkowski, M.; Liebregts, T.; Lindemann, M.; Heinemann, F. M.; Horn, P. A.; Beelen, D. W. \& Rebmann, V. Elevated soluble human leukocyte antigen $\mathrm{G}$ levels in patients after allogeneic stem cell transplantation are associated with less severe acute and chronic graft-versus-host disease. Bone Marrow Transplant., 53(9):1149-56, 2018.

Kwak, K. A.; Cho, H. J.; Yang, J. Y. \& Park, Y. S. Current perspectives regarding stem cell-based therapy for liver cirrhosis. Can. J. Gastroenterol. Hepatol., 2018:4197857, 2018.

Lee, U. E. \& Friedman, S. F. Mechanisms of hepatic fibrogenesis. Best Pract. Res. Clin. Gastroenterol., 25(2):195-206, 2011.
Li, C.; Li, R. \& Zhang, W. Progress in non-invasive detection of liver fibrosis. Cancer Biol. Med., 15(2):124-36, 2018.

Mederacke, I.; Hsu, C. C.; Troeger, J. S.; Huebener, P.; Mu, X.; Dapito, D. H.; Pradere, J. P. \& Schwabe, R. F. Fate tracing reveals hepatic stellate cells as dominant contributors to liver fibrosis independent of its aetiology. Nat. Commun., 4:2823, 2013.

Miko, M.; Danisovic, L.; Majidi, A. \& Varga, I. Ultrastructural analysis of different human mesenchymal stem cells after in vitro expansion: a technical review. Eur. J. Histochem., 59(4):2528, 2015.

Nallagangula, K. S.; Nagaraj, S. K.; Venkataswamy, L. \& Chandrappa, M. Liver fibrosis: a compilation on the biomarkers status and their significance during disease progression. Future Sci. OA, 4(1):FSO250, 2018

Nascimento, M.; Piran, R.; Da Costa, R. M.; Giordani, M. A.; Carneiro, F. S.; Aguiar, D. H., Dias, M. C., Sugizaki, M. M., Luvizotto, R. A.; Nascimento, A. F.; et al. Hepatic injury induced by thioacetamide causes aortic endothelial dysfunction by a cyclooxygenase-dependent mechanism. Life Sci., 212:168-75, 2018.

Perez, H. R. \& Stoeckle, H. J. Stuttering: clinical and research update. Can. Fam. Physician, 62(6):479-84, 2016.

Sica, A.; Invernizzi, P. \& Mantovani, A. Macrophage plasticity and polarization in liver homeostasis and pathology. Hepatology, 59(5):2034-42, 2014.

Wang, Y.; Chen, X.; Cao, W. \& Shi, Y. Plasticity of mesenchymal stem cells in immunomodulation: pathological and therapeutic implications. Nat. Immunol., 15(11):1009-16, 2014.

Zhu, W.; Shi, X. L.; Xiao, J. Q.; Gu, G. X.; Ding Y. T. \& Ma, Z. L. Effects of xenogeneic adipose-derived stem cell transplantation on acute-on-chronic liver failure. Hepatobiliary Pancreat. Dis. Int., 12(1):60-7, 2013.

Dirección para correspondencia:

Javier Enciso Gutiérrez

Laboratorio de Cultivo Celular e Inmunología

Universidad Científica del Sur

Lima

PERÚ

Email: jenciso@cientifica.edu.pe

Recibido : 01-05-2020

Aceptado: 09-06-2020 